\title{
Is preeclampsia itself a risk factor for the development of metabolic syndrome after delivery?
}

\author{
Geum Joon Cho ${ }^{1, *}$, Un Suk Jung ${ }^{2,}$, Jae Young Sim ${ }^{1}$, Yoo Jin Lee ${ }^{1}$, Na Young Bae ${ }^{1}$, Hye Jin Choi ${ }^{1}$, \\ Jong Heon Park ${ }^{3}$, Hai-Joong Kim ${ }^{1}$, Min-Jeong $\mathrm{Oh}^{1}$ \\ Department of Obstetrics and Gynecology, ${ }^{1}$ Korea University College of Medicine, Seoul, ${ }^{2}$ Hanyang University Guri Hospital, College of Medicine, \\ Hanyang University, Guri, Korea; ${ }^{3}$ Big Data Steering Department, National Health Insurance Service, Wonju, Korea
}

\section{Objective}

This study aimed to determine the association between preeclampsia and the postpartum development of metabolic syndrome based on the pre-pregnancy status.

\section{Methods}

Korean women who delivered their first child between January 1, 2011, and December 31, 2012, were enrolled. All subjects underwent a national health screening examination conducted by the National Health Insurance Corporation 1 or 2 years prior to their first delivery and within 2 years after their first delivery.

Results

Among the 49,065 participants, preeclampsia developed in 3,391 participants (6.9\%). The prevalence of metabolic syndrome was higher postpartum in women with preeclampsia than in those without preeclampsia $(4.9 \%$ vs. $2.7 \%$, respectively, $P<0.001)$. Through the pre-pregnancy to postpartum period, women with preeclampsia had a greater increase in gestational weight retention, body mass index, waist circumference, systolic blood pressure, and triglyceride levels and a greater decrease in high-density lipoprotein cholesterol levels than women without preeclampsia. Preeclampsia was associated with an increased risk of the postpartum development of metabolic syndrome in women without pre-pregnancy metabolic syndrome (odds ratio, 1.28; 95\% confidence interval, 1.05-1.56). However, preeclampsia was not associated with postpartum metabolic syndrome in women with pre-pregnancy metabolic syndrome or 2 components of metabolic syndrome.

\section{Conclusion}

In this study, preeclampsia was associated with the postpartum development of metabolic syndrome in women without pre-pregnancy metabolic syndrome. However, the effects were attenuated by predisposing risk factors in the pre-pregnancy period.

Keywords: Preeclampsia; Metabolic syndrome; Cardiovascular disease; Diabetes mellitus; Hypertension

\section{Introduction}

Preeclampsia is a pregnancy complication characterized by hypertension (HTN) and proteinuria after 20 weeks' gestation and is seen in $2-8 \%$ of pregnancies [1]. Complications of preeclampsia include prematurity, intrauterine growth restriction, and placental abruption [2,3]. Although high blood pressure (BP) typically normalizes after delivery, women with preeclampsia are at increased risk for eventually developing HTN $[4,5]$. These women are at higher risk of future diabetes mellitus (DM), stroke, and cardiovascular disease (CVD) as well as increased overall mortality rates [4-7]. However, it
Received: 2018.08.06. Revised: 2018.12.31. Accepted: 2019.01.22. Corresponding author: Min-Jeong Oh

Department of Obstetrics and Gynecology, Korea University Guro Hospital, Korea University College of Medicine, 148 Gurodong-ro, Guro-gu, Seoul 08308, Korea

E-mail: mjohmd@korea.ac.kr https://orcid.org/0000-0002-3130-2728

*These authors contributed equally to this work.

Articles published in Obstet Gynecol Sci are open-access, distributed under the terms of the Creative Commons Attribution Non-Commercial License (http://creativecommons. org/licenses/by-nc/3.0/) which permits unrestricted non-commercial use, distribution, and reproduction in any medium, provided the original work is properly cited.

Copyright $\odot 2019$ Korean Society of Obstetrics and Gynecology 


\title{
Obstetrics \& Gynecology Science
}

\author{
Vol. 62, No. 4, 2019
}

remains unclear whether the development of preeclampsia itself predisposes women to long-term CVD or simply arises in women with an underlying susceptibility to future CVD [2]. It is generally believed that preeclampsia does not predispose a woman to CVD; rather, preeclampsia and CVD share common risk factors [8].

Metabolic syndrome, an assembly of metabolic disorders, is associated with an increased risk of the above conditions [9-11]. A recent study found that preeclampsia is associated with an increased risk of postpartum metabolic syndrome [12-15], implying its role in the pathophysiology that ultimately leads to CVD [13]. However, none of these studies included pre-pregnancy metabolic assessments; therefore, the presence of metabolic syndrome before pregnancy remains uncertain.

Thus, the aim of this study was to investigate the association between preeclampsia and the postpartum development of metabolic syndrome based on the pre-pregnancy status.

\section{Materials and methods}

\section{Healthcare delivery system in South Korea}

The study was conducted using data from the Korea National Health Insurance (KNHI) Claims Database from 2009 to 2014. Of the total Korean population, $97 \%$ is obligated to enroll in the $\mathrm{KNHI}$ program, while the remaining 3\% of Korean population is covered by the Medical Aid Program. Thus, the KNHI Claims Database contains information on all claims for diseases and procedures covered by the national health insurance. The KNHI healthcare system also includes a biannual national health screening examination (NHSE) provided to all insurance subscribers and dependents.

\section{Study population}

Among all women in Korea who delivered their first baby between January 1, 2011, and December 31, 2012, those who underwent an NHSE 1-2 years before their first delivery and within 2 years after their first delivery were included. The time before delivery was defined as the time from the prepregnancy measurement to the first delivery. The time after delivery was defined as the time from the first delivery to the postpartum measurement. Gestational weight retention was determined by subtracting the woman's weight at a prepregnancy visit from her weight at a postpartum visit. Pre- eclampsia was identified by the International Classification of Diseases-10th revision (ICD-10 codes 012, 013, 014, and 015).

\section{Measurement of pre-pregnancy and postpartum characteristics}

Data from the NHSE consisting of a health interview and a health examination were used to evaluate pre-pregnancy and postpartum factors of the study population. Information on the participants' age and smoking status, covariates in the study, were obtained from the health interview. Participants were divided into 3 categories according to smoking status: current, past, and never. As employee health insurance premiums reflect a worker's salary, the study used premiums as a substitute variable for income level. Pre-pregnancy insurance premiums were classified into 5 quintiles of performance, with the highest income level in Q5.

During the health examination, each participant's body mass index $\left(\mathrm{BMl}, \mathrm{kg} / \mathrm{m}^{2}\right)$, waist circumference (WC) measured at the approximate midpoint between the lower margin of the last palpable rib and the top of the iliac crest, and BP were measured. BP was measured with a standard mercury sphygmomanometer. All participants were required to fast a minimum of 8 hours before the blood samples were obtained. The levels of fasting blood sugar, total cholesterol (TC), triglycerides (TG), high-density lipoprotein cholesterol (HDL-C), and low-density lipoprotein cholesterol (LDL-C) were measured using enzymatic methods. Women with a BP $\geq 140 / 90 \mathrm{mmHg}$ at the NHSE $(n=152)$ without a diagnosis of HTN were excluded, as were those with previously diagnosed HTN ( $n=123)$.

\section{Definition of metabolic syndrome}

The National Cholesterol Education Program Adult Treatment Panel III Criteria for metabolic syndrome [11] except those for abdominal obesity were used in this study. Cutoffs established for Korean adults as proposed by the Korean Society for the Study of Obesity [16] were used to evaluate abdominal obesity. The American Diabetes Association guideline was used to evaluate high blood glucose levels [17].

Any 3 or more of the following traits in the same individual met the criteria for metabolic syndrome: 1) high WC, $\geq 85 \mathrm{~cm}$; 2) high $B P, \geq 130 / 85 \mathrm{mmHg}$ or currently on antihypertensive medication; 3) high fasting glucose level, $\geq 100 \mathrm{mg} / \mathrm{dL}$ or currently being treated for $\mathrm{DM}$; 4) low HDL-C, $<50 \mathrm{mg} / \mathrm{dL}$; and 5) 


\section{Obstetrics \& Gynecology Science}

Geum Joon Cho, et al. Metabolic syndrome after preeclampsia

high TG, $\geq 150 \mathrm{mg} / \mathrm{dL}$.

\section{Statistical analysis}

Continuous and categorical variables are expressed as mean \pm standard deviation and percentages, respectively. Among the groups, the $t$-test was used to compare the differences in continuous variables, while the $\chi^{2}$ test was used to examine categorical variables. Analysis of covariance was used to compare changes in anthropometric characteristics and components of metabolic syndrome across the prepregnancy and postpartum periods after the adjustment for covariates including age, pre-pregnancy BMl, smoking status, insurance premiums, and time before pregnancy and after delivery. Using multivariate logistic regression analysis, we calculated the adjusted odds ratio (OR) and 95\% confidence interval $(\mathrm{Cl})$ for the postoperative development of metabolic syndrome. We performed the statistical analysis using SAS for Windows, version 9.4 (SAS Inc., Cary, NC, USA).

\section{Results}

Among the 49,065 participants, preeclampsia developed in 3,391 (6.9\%). Table 1 represents the pre-pregnancy characteristics of women who were diagnosed with preeclampsia in their first pregnancy. Women with preeclampsia tended to

Table 1. Clinical and biochemical characteristics of the study participants

\begin{tabular}{|c|c|c|c|}
\hline Variables & No preeclampsia $(n=45,674)$ & Preeclampsia $(n=3,391)$ & $P$-value \\
\hline Age (yr) & $30.73 \pm 3.24$ & $30.92 \pm 3.29$ & 0.001 \\
\hline Time before delivery (mon) & $17.88 \pm 3.39$ & $17.96 \pm 3.37$ & 0.188 \\
\hline Time after delivery (mon) & $9.98 \pm 5.36$ & $9.85 \pm 5.32$ & 0.145 \\
\hline Smoking status & & & 0.006 \\
\hline Never & 94.3 & 93.0 & \\
\hline Past & 3.0 & 3.7 & \\
\hline Current & 2.7 & 3.3 & \\
\hline Insurance premiums ${ }^{\mathrm{a})}$ & & & $<0.001$ \\
\hline Q1 & 6.0 & 7.1 & \\
\hline Q2 & 11.6 & 13.0 & \\
\hline Q3 & 31.8 & 31.7 & \\
\hline Q4 & 38.3 & 38.3 & \\
\hline Q5 & 12.3 & 9.9 & \\
\hline Pre-pregnancy weight (kg) & $53.40 \pm 6.94$ & $54.68 \pm 7.97$ & $<0.001$ \\
\hline Pre-pregnancy height (cm) & $161.43 \pm 5.07$ & $161.14 \pm 5.16$ & 0.001 \\
\hline Pre-pregnancy BMI (kg/m²) & $20.48 \pm 2.44$ & $21.05 \pm 2.85$ & $<0.001$ \\
\hline Pre-pregnancy WC (cm) & $68.50 \pm 6.43$ & $69.51 \pm 7.16$ & $<0.001$ \\
\hline Pre-pregnancy systolic BP (mmHg) & $109.50 \pm 10.13$ & $111.12 \pm 11.74$ & $<0.001$ \\
\hline Pre-pregnancy diastolic BP (mmHg) & $68.85 \pm 7.59$ & $69.99 \pm 7.81$ & $<0.001$ \\
\hline Pre-pregnancy FBS level (mg/dL) & $87.01 \pm 9.51$ & $87.78 \pm 10.72$ & $<0.001$ \\
\hline Pre-pregnancy TC level (mg/dL) & $176.09 \pm 28.22$ & $177.42 \pm 29.31$ & 0.008 \\
\hline Pre-pregnancy HDL-C level (mg/dL) & $63.44 \pm 13.11$ & $62.72 \pm 13.20$ & 0.002 \\
\hline Pre-pregnancy TG level (mg/dL) & $73.57 \pm 43.11$ & $78.93 \pm 52.01$ & $<0.001$ \\
\hline Pre-pregnancy LDL-C level (mg/dL) & $97.80 \pm 25.14$ & $99.00 \pm 26.36$ & 0.008 \\
\hline
\end{tabular}

Values are expressed as mean \pm standard deviation or number (\%).

BMI, body mass index; WC, waist circumference; BP, blood pressure; TC, total cholesterol; TG, triglycerides; HDL-C, high-density lipoprotein cholesterol; LDL-C, low-density lipoprotein cholesterol; FBS, fasting blood sugar.

a)Pre-pregnancy insurance premiums as are classified into 5 quintiles of performance, with the highest income level in Q5. 


\title{
Obstetrics \& Gynecology Science
}

\author{
Vol. 62, No. 4, 2019
}

be older and more likely to have a family history of HTN than those without preeclampsia. The pre-pregnancy BMI, WC, and BP as well as fasting glucose, TC, TG, and LDL-C levels were higher and $\mathrm{HDL}-\mathrm{C}$ levels were lower in women with preeclampsia than in those without preeclampsia. The distributions of smoking status and insurance premiums differed between the 2 groups. However, time before pregnancy and after delivery did not differ between the 2 groups.

Women with preeclampsia were more likely to show abnormalities in the components of metabolic syndrome and a subsequently higher prevalence of metabolic syndrome before pregnancy than women without preeclampsia (Table 2).

Table 2. The prevalence of metabolic syndrome and abnormalities of its components according to presence or absence of preeclampsia

\begin{tabular}{lccc}
\hline Variables & No preeclampsia $(\mathbf{n = 4 5 , 6 7 4 )}$ & Preeclampsia $(\mathbf{n = 3 , 3 9 1 )}$ & $\boldsymbol{P}$-value \\
\hline Pre-pregnancy & & & $<0.001$ \\
Metabolic syndrome & 0.9 & 1.9 & $<0.001$ \\
High WC & 2.1 & 3.6 & $<0.001$ \\
High BP & 5.1 & 8.7 & $<0.001$ \\
High FBS & 7.8 & 9.6 & 0.018 \\
Low HDL-C & 13.3 & 14.7 & $<0.001$ \\
High TG & 3.8 & 5.7 & $<0.001$ \\
Post-delivery & & & $<0.001$ \\
Metabolic syndrome & 2.7 & 4.9 & $<0.001$ \\
High WC & 7.6 & 11.1 & $<0.001$ \\
High BP & 4.9 & 10.3 & $<0.001$ \\
High FBS & 9.5 & 11.5 & $<0.001$ \\
Low HDL-C & 21.1 & 25.5 & \\
High TG & 9.7 & 12.9 & \\
\hline
\end{tabular}

Values are expressed as number (\%).

High WC, WC $\geq 85 \mathrm{~cm}$; High BP, systolic/diastolic BP $\geq 130 / 85 \mathrm{mmHg}$ or on antihypertensive medication; High FBS, glucose level $\geq 100 \mathrm{mg} / \mathrm{dL}$ or receiving treatment for diabetes; Low HDL-C, HDL-C level $<50 \mathrm{mg} / \mathrm{dL}$; High TG, TG level $\geq 150 \mathrm{mg} / \mathrm{dL}$.

WC, waist circumference; BP, blood pressure; FBS, fasting blood sugar; HDL-C, high-density lipoprotein cholesterol; TG, triglycerides.

Table 3. (hanges ${ }^{a)}$ in anthropometry and components of metabolic syndrome

\begin{tabular}{lccc}
\hline Variables & No preeclampsia $(\mathbf{n}=\mathbf{4 5 , 6 7 4 )}$ & Preeclampsia $(\mathbf{n}=\mathbf{3 , 3 9 1})$ & $\boldsymbol{P}$-value \\
\hline Gestational weight retention $(\mathrm{kg})$ & $2.72 \pm 0.02$ & $2.99 \pm 0.07$ & $<0.001$ \\
BMI $\left(\mathrm{kg} / \mathrm{m}^{2}\right)$ & $1.10 \pm 0.01$ & $1.21 \pm 0.03$ & $<0.001$ \\
WC $(\mathrm{cm})$ & $4.20 \pm 0.03$ & $4.44 \pm 0.12$ & 0.043 \\
Systolic BP $(\mathrm{mmHg})$ & $-0.72 \pm 0.06$ & $0.05 \pm 0.21$ & $<0.001$ \\
Diastolic BP (mmHg) & $-0.65 \pm 0.04$ & $-0.39 \pm 0.16$ & 0.124 \\
Fasting glucose (mg/dL) & $0.81 \pm 0.06$ & $0.78 \pm 0.21$ & 0.870 \\
Total cholesterol (mg/dL) & $4.87 \pm 0.13$ & $4.20 \pm 0.49$ & 0.181 \\
HDL (mg/dL) & $-3.07 \pm 0.06$ & $-3.89 \pm 0.23$ & $<0.001$ \\
TG (mg/dL) & $15.06 \pm 0.28$ & $17.23 \pm 1.02$ & 0.040 \\
LDL (mg/dL) & $5.05 \pm 0.12$ & $4.60 \pm 0.43$ & 0.415 \\
\hline
\end{tabular}

Values are expressed as adjusted means \pm standard deviation.

BMI, body mass index; WC, waist circumference; BP, blood pressure; HDL, high-density lipoprotein; TG, triglycerides; LDL, low-density lipoprotein.

${ }^{a)}$ Adjusted for age, pre-pregnancy BMI, smoking status, insurance premiums, time before pregnancy, and time after pregnancy. 


\section{Obstetrics \& Gynecology Science}

Geum Joon Cho, et al. Metabolic syndrome after preeclampsia

The postpartum prevalences of metabolic syndrome and component abnormalities were also higher in women who developed preeclampsia (Table 2).

Table 3 shows the changes in the anthropometric characteristics and components of metabolic syndrome through the pre-pregnancy to postpartum periods. Women with preeclampsia had a greater increase in gestational weight retention, BMI, WC, systolic BP, and TG levels and a greater decrease in HDL-C levels than women without preeclampsia. However, there were no intergroup differences in changes in diastolic BP and fasting glucose, TC, or LDL-C levels.

Table 4 shows the risk of developing postpartum metabolic syndrome. Among all women, those with preeclampsia were more likely to develop postpartum metabolic syndrome (OR,
1.34; $95 \% \mathrm{Cl}, 1.11-1.61)$ than those without preeclampsia after the adjustment for confounding factors. Among women without pre-pregnancy metabolic syndrome, preeclampsia was associated with an increased risk of the development of metabolic syndrome (OR, 1.28; 95\% Cl, 1.05-1.56). However, among women who had metabolic syndrome before pregnancy, preeclampsia was not associated with the postpartum development of metabolic syndrome (OR, 1.62; 95\% $\mathrm{Cl}, 0.92-2.85)$.

The risk of developing metabolic syndrome postpartum according to the number of components of metabolic syndrome in the pre-pregnancy period is shown in Table 5. Preeclampsia was associated with an increased risk of the postpartum development of metabolic syndrome in women with

Table 4. The risk of developing metabolic syndrome after delivery according to absence and presence of metabolic syndrome in the prepregnancy period

\begin{tabular}{lccc}
\hline Variables & $\begin{array}{c}\text { All women } \\
(\mathbf{n = 4 9 , 0 6 5 )}\end{array}$ & $\begin{array}{c}\text { Women without pre-pregnancy } \\
\text { metabolic syndrome (n=45,594) }\end{array}$ & $\begin{array}{c}\text { Women with pre-pregnancy } \\
\text { metabolic syndrome (n=471) }\end{array}$ \\
\hline Age & $1.03(1.01-1.04)$ & $1.03(1.01-1.04)$ & $1.03(0.98-1.08)$ \\
Smoking status & 1 & 1 & 1 \\
$\quad$ Never & $1.42(1.09-1.84)$ & $1.50(1.15-1.96)$ & $0.75(0.30-1.90)$ \\
Past & $1.43(1.09-1.88)$ & $1.41(1.06-1.89)$ & $1.69(0.83-3.46)$ \\
$\quad$ Current & 1 & 1 & 1 \\
Insurance premiums & $1.05(0.82-1.34)$ & $1.10(0.85-1.43)$ & $0.67(0.30-1.50)$ \\
Q1 & $0.92(0.74-1.15)$ & $0.96(0.76-1.21)$ & $0.71(0.34-1.46)$ \\
Q2 & $0.77(0.62-0.97)$ & $0.83(0.65-1.05)$ & $0.45(0.21-0.94)$ \\
Q3 & $0.82(0.63-1.06)$ & $0.81(0.61-1.07)$ & $0.89(0.40-2.02)$ \\
Q4 & $1.38(1.36-1.40)$ & $1.41(1.38-1.43)$ & $1.15(1.09-1.21)$ \\
Q5 & $3.49(2.73-4.45)$ & - & -
\end{tabular}

Values are presented as median (interquartile range) or number (\%). The model is adjusted for variables in the table.

$\mathrm{BMI}$, body mass index.

Table 5. The risk ${ }^{\text {a) }}$ of developing metabolic syndrome after delivery for preeclampsia according to number of components of metabolic syndrome in the pre-pregnancy period

\begin{tabular}{lccccc}
\hline \multirow{2}{*}{ Variables } & \multicolumn{5}{c}{ Women } \\
\cline { 2 - 6 } & No component & $\mathbf{1}$ component & $\mathbf{2}$ components & $\mathbf{3}$ components & $\mathbf{4}$ components \\
\hline Preeclampsia & $1.66(1.24-2.21)$ & $1.50(1.11-2.01)$ & $1.21(0.80-1.85)$ & $1.51(0.80-2.85)$ & $1.79(0.55-5.82)$
\end{tabular}

Values are presented as median (interquartile range).

${ }^{\text {a) }}$ Adjusted for age, pre-pregnancy body mass index, smoking status, insurance premiums, time before pregnancy and time after pregnancy. 


\section{Obstetrics \& Gynecology Science}

Vol. 62, No. 4, 2019

0 or 1 components of pre-pregnancy metabolic syndrome, but there was no association in women with 2 or more components.

Among women with preeclampsia, 81.8\% (131/165) of those who developed postpartum metabolic syndrome did not have pre-pregnancy metabolic syndrome. In particular, $31.5 \%$ (52/165) did not have any components of metabolic syndrome. In contrast, $18.2 \%$ of women who developed postpartum metabolic syndrome already had metabolic syndrome in the pre-pregnancy period, and $68.5 \%$ of these had 1 or more components of metabolic syndrome.

\section{Discussion}

Here we evaluated the association between preeclampsia and the postpartum development of metabolic syndrome based on the pre-pregnancy status. Among women without pre-pregnancy metabolic syndrome, preeclampsia was associated with an increased risk of the postpartum development of metabolic syndrome. Even in women without any elements of metabolic syndrome in the pre-pregnancy period, preeclampsia was associated with an increased risk of development of metabolic syndrome in the postpartum period.

The potential mechanisms that may link preeclampsia with the postpartum development of metabolic syndrome are not well understood. Pregnancy is associated with weight gain [18], particularly the accumulation and redistribution of body fat [19], which is related to insulin resistance, CVD, and DM $[20,21]$. Moreover, physiological adaptations that occur during pregnancy result in insulin resistance [22] and atherogenic dyslipidemia as well as increases in cholesterol and triglyceride levels $[23,24]$. In contrast, in preeclampsia, the physiological changes in weight, insulin resistance, and lipids are exaggerated [25-28] and can lead to metabolic disturbances. In fact, although women with preeclampsia already had abnormal levels of the components of metabolic syndrome in the pre-pregnancy period, exaggerated changes in the components were found in women with preeclampsia versus women without preeclampsia. This suggests that preeclampsia itself may have an independent effect on the development of metabolic syndrome in the postpartum period through perturbations in multiple metabolic pathways. In contrast, among women who already had pre-pregnancy metabolic syndrome, preeclampsia was not an additional risk factor for the postpartum development of metabolic syndrome. These results suggest that the contribution of preeclampsia to the development of metabolic syndrome is attenuated by the contribution of factors that were present before pregnancy [29].

In this study, women affected by preeclampsia were more likely to develop metabolic syndrome as reported in other studies [12-15]. However, it remains unclear whether preeclampsia itself potentiates the postpartum development of metabolic syndrome or preeclampsia arises in women with predisposing conditions for metabolic syndrome. When the link between preeclampsia and the postpartum development of metabolic syndrome was evaluated only among women with preeclampsia, $31.5 \%$ did not have any of the components of metabolic syndrome in the pre-pregnancy period. This also means that $68.5 \%$ already had 1 or more components. Therefore, it is likely that the underlying association between preeclampsia and the development of metabolic syndrome is a combination of both possibilities [30].

Based on our results, a structured assessment may lower the risk of metabolic syndrome related to preeclampsia. First, the early identification and intervention, such as lifestyle modifications, may be suggested for women at high risk of developing preeclampsia to lower their risk. It is possible for women with preeclampsia but with no metabolic abnormalities to develop metabolic syndrome in the postpartum period. Thus, preeclampsia should be recognized as a major risk factor for the development of metabolic syndrome, and early interventions should be provided with the goal of primary prevention [31].

There are several limitations in the interpretations of these findings. First, preeclampsia severity, gestational age at delivery, and neonatal outcome, which are known to be associated with the development of CVD, were not reflected $[6,32,33]$. Data about postpartum lifestyle, such as breastfeeding or physical activity, both of which effectively reduce cardiovascular risk $[34,35]$, were also not available. Therefore, further studies are needed to evaluate the differences in these potentially confounding factors between women with and those without preeclampsia. Second, in this study, since pre-pregnancy metabolic syndrome was evaluated, it is possible that women without pre-pregnancy metabolic syndrome will develop metabolic syndrome early in pregnancy; thereafter, preeclampsia is first diagnosed in the absence of a diagnosis of metabolic syndrome, although we attempted to 


\section{Obstetrics \& Gynecology Science}

Geum Joon Cho, et al. Metabolic syndrome after preeclampsia

correct these problems by adjusting for risk factors such prepregnancy BMI and the time before delivery. However, there is no definition of metabolic syndrome specific to pregnancy. Moreover, AC, a component of metabolic syndrome, will increase significantly as gestational weeks increase. Thus, it is difficult to diagnose metabolic syndrome during pregnancy. Finally, the diagnosis of preeclampsia was based on ICD-10 codes from the KNHI Claims Database. Thus, the validity of the diagnosis is another limitation. There are no formal validation studies of the diagnoses of preeclampsia in the $\mathrm{KNHI}$ Claims Database of Korea. However, the KNHI Claims Database includes the entire Korean population; thus, it is the most reliable data for assessing healthcare utilization of the Korean population [36]. According to a previous validation study that compared diagnoses from the database to the actual diagnoses documented in the patients' medical records, KNHI Claims Data had an $83.4 \%$ overall positive predictive value in the cases of hospitalized patients $[37,38]$. The diagnostic codes were also more accurate for claims involving conditions with higher severity, such as preeclampsia $[39,40]$.

Nevertheless, the strength of the present study lies in its large population-based cohort in which metabolic syndrome was assessed both before pregnancy and after delivery. Moreover, to minimize the effect of parity, we enrolled only women who had delivered their first child during the study period. Our robust metabolic assessments provide important information about the metabolic changes that occur from pre-pregnancy to the postpartum period according to the presence of preeclampsia.

In conclusion, our study demonstrated that preeclampsia was associated with an increased risk of the postpartum development of metabolic syndrome in women without pre-pregnancy metabolic syndrome, but this finding was attenuated by predisposing risk factors for metabolic syndrome in the pre-pregnancy period. Further studies with long-term follow-up periods are needed to compare the development of future CVD between preeclamptic women with newly developed metabolic syndrome and those with pre-pregnancy metabolic syndrome or predisposing risk factors.

\section{Acknowledgements}

This work was supported by the National Research Foundation of Korea Grant funded by the Korean Government (NRF-
2012R1A1A1044719).

\section{Conflict of interest}

No potential conflict of interest relevant to this article was reported.

\section{Ethical approval}

The Institutional Review Board of Korea University Medical Center (IRB No.2016GR0093) reviewed and approved this study.

\section{REFERENCES}

1. Duley L. The global impact of pre-eclampsia and eclampsia. Semin Perinatol 2009;33:130-7.

2. Koonin LM, MacKay AP, Berg CJ, Atrash HK, Smith JC. Pregnancy-related mortality surveillance--United States, 1987-1990. MMWR CDC Surveill Summ 1997;46:1736.

3. Hauth JC, Ewell MG, Levine RJ, Esterlitz JR, Sibai B, Curet $L B$, et al. Pregnancy outcomes in healthy nulliparas who developed hypertension. Calcium for preeclampsia prevention study group. Obstet Gynecol 2000;95:24-8.

4. Hannaford P, Ferry S, Hirsch S. Cardiovascular sequelae of toxaemia of pregnancy. Heart 1997;77:154-8.

5. Wilson BJ, Watson MS, Prescott GJ, Sunderland S, Campbell DM, Hannaford P, et al. Hypertensive diseases of pregnancy and risk of hypertension and stroke in later life: results from cohort study. BMJ 2003;326:845.

6. Smith GC, Pell JP, Walsh D. Pregnancy complications and maternal risk of ischaemic heart disease: a retrospective cohort study of 129,290 births. Lancet 2001;357:20026.

7. Feig DS, Shah BR, Lipscombe LL, Wu CF, Ray JG, Lowe J, et al. Preeclampsia as a risk factor for diabetes: a population-based cohort study. PLoS Med 2013;10:e1001425.

8. American College of Obstetricians and Gynecologists; Task Force on Hypertension in Pregnancy. Hypertension in pregnancy. Report of the American College of Obstetricians and Gynecologists' task force on hypertension in 


\title{
Obstetrics \& Gynecology Science
}

\author{
Vol. 62, No. 4, 2019
}

pregnancy. Obstet Gynecol 2013;122:1122-31.

9. Ninomiya JK, L'Italien G, Criqui MH, Whyte JL, Gamst A, Chen RS. Association of the metabolic syndrome with history of myocardial infarction and stroke in the Third National Health and Nutrition Examination Survey. Circulation 2004;109:42-6.

10. Ford ES. Risks for all-cause mortality, cardiovascular disease, and diabetes associated with the metabolic syndrome: a summary of the evidence. Diabetes Care 2005;28:1769-78.

11. Expert Panel on Detection, Evaluation, and Treatment of High Blood Cholesterol in Adults. Executive summary of the third report of the national cholesterol education program (NCEP) expert panel on detection, evaluation, and treatment of high blood cholesterol in adults (Adult Treatment Panel III). JAMA 2001;285:2486-97.

12. Pouta A, Hartikainen AL, Sovio U, Gissler M, Laitinen J, McCarthy Ml, et al. Manifestations of metabolic syndrome after hypertensive pregnancy. Hypertension 2004;43:825-31.

13. Forest JC, Girouard J, Massé J, Moutquin JM, Kharfi $A$, Ness RB, et al. Early occurrence of metabolic syndrome after hypertension in pregnancy. Obstet Gynecol 2005;105:1373-80.

14. Yang JJ, Lee SA, Choi JY, Song M, Han S, Yoon HS, et al. Subsequent risk of metabolic syndrome in women with a history of preeclampsia: data from the health examinees study. J Epidemiol 2015;25:281-8.

15. Smith GN, Pudwell J, Walker M, Wen SW. Risk estimation of metabolic syndrome at one and three years after a pregnancy complicated by preeclampsia. J Obstet Gynaecol Can 2012;34:836-41.

16. Lee SY, Park HS, Kim DJ, Han JH, Kim SM, Cho GJ, et al. Appropriate waist circumference cutoff points for central obesity in Korean adults. Diabetes Res Clin Pract 2007;75:72-80.

17. Genuth S, Alberti KG, Bennett P, Buse J, Defronzo R, Kahn $R$, et al. Follow-up report on the diagnosis of diabetes mellitus. Diabetes Care 2003;26:3160-7.

18. Smith DE, Lewis CE, Caveny JL, Perkins LL, Burke GL, Bild DE. Longitudinal changes in adiposity associated with pregnancy. The cardia study. Coronary artery risk development in young adults study. JAMA 1994;271:174751.

19. Cho GJ, Yoon HJ, Kim EJ, Oh MJ, Seo HS, Kim HJ. Post- partum changes in body composition. Obesity (Silver Spring) 2011;19:2425-8.

20. Rönnemaa T, Koskenvuo M, Marniemi J, Koivunen T, Sajantila A, Rissanen A, et al. Glucose metabolism in identical twins discordant for obesity. The critical role of visceral fat. J Clin Endocrinol Metab 1997;82:383-7.

21. Onat A, Avci GS, Barlan MM, Uyarel H, Uzunlar B, Sansoy $\mathrm{V}$. Measures of abdominal obesity assessed for visceral adiposity and relation to coronary risk. Int J Obes Relat Metab Disord 2004;28:1018-25.

22. Catalano PM, Tyzbir ED, Roman NM, Amini SB, Sims EA. Longitudinal changes in insulin release and insulin resistance in nonobese pregnant women. Am J Obstet Gynecol 1991;165:1667-72.

23. Potter JM, Nestel PJ. The hyperlipidemia of pregnancy in normal and complicated pregnancies. Am J Obstet Gynecol 1979;133:165-70.

24. Alvarez JJ, Montelongo A, Iglesias A, Lasunción MA, Herrera E. Longitudinal study on lipoprotein profile, high density lipoprotein subclass, and postheparin lipases during gestation in women. J Lipid Res 1996;37:299308.

25. Truong YN, Yee LM, Caughey AB, Cheng YW. Weight gain in pregnancy: does the Institute of Medicine have it right? Am J Obstet Gynecol 2015;212:362.e1-362.e8.

26. Kaaja R, Laivuori H, Laakso M, Tikkanen MJ, Ylikorkala $O$. Evidence of a state of increased insulin resistance in preeclampsia. Metabolism 1999;48:892-6.

27. Wiznitzer A, Mayer A, Novack V, Sheiner E, Gilutz H, Malhotra $A$, et al. Association of lipid levels during gestation with preeclampsia and gestational diabetes mellitus: a population-based study. Am J Obstet Gynecol 2009;201:482.e1-482.e8.

28. Hermes W, Ket JC, van Pampus MG, Franx A, Veenendaal MV, Kolster $C$, et al. Biochemical cardiovascular risk factors after hypertensive pregnancy disorders: a systematic review and meta-analysis. Obstet Gynecol Surv 2012;67:793-809.

29. Romundstad PR, Magnussen EB, Smith GD, Vatten LJ. Hypertension in pregnancy and later cardiovascular risk: common antecedents? Circulation 2010;122:579-84.

30. Rodie VA, Freeman DJ, Sattar N, Greer IA. Pre-eclampsia and cardiovascular disease: metabolic syndrome of pregnancy? Atherosclerosis 2004;175:189-202.

31. Mosca L, Benjamin EJ, Berra K, Bezanson JL, Dolor RJ, 


\section{Obstetrics \& Gynecology Science}

Geum Joon Cho, et al. Metabolic syndrome after preeclampsia

Lloyd-Jones DM, et al. Effectiveness-based guidelines for the prevention of cardiovascular disease in women--2011 update: a guideline from the American Heart Association. Circulation 2011;123:1243-62.

32. Veerbeek JH, Hermes W, Breimer AY, van Rijn BB, Koenen SV, Mol BW, et al. Cardiovascular disease risk factors after early-onset preeclampsia, late-onset preeclampsia, and pregnancy-induced hypertension. Hypertension 2015;65:600-6.

33. Irgens $H U$, Reisaeter L, Irgens LM, Lie RT. Long term mortality of mothers and fathers after pre-eclampsia: population based cohort study. BMJ 2001;323:1213-7.

34. Schwarz EB, McClure CK, Tepper PG, Thurston R, Janssen I, Matthews KA, et al. Lactation and maternal measures of subclinical cardiovascular disease. Obstet Gynecol 2010;115:41-8.

35. Scholten RR, Thijssen DJ, Lotgering FK, Hopman MT, Spaanderman ME. Cardiovascular effects of aerobic exercise training in formerly preeclamptic women and healthy parous control subjects. Am J Obstet Gynecol 2014;211:516.e1-516.e11.
36. Kang HY, Lim SJ, Suh HS, Liew D. Estimating the lifetime economic burden of stroke according to the age of onset in South Korea: a cost of illness study. BMC Public Health 2011;11:646.

37. Park BJ, Sung JH, Park KD, Seo SW, Kim SW. Report of the evaluation for validity of discharged diagnoses in Korean health insurance database. Seoul: Seoul National University; 2003.

38. Park JK, Kim KS, Kim CB, Lee TY, Lee KS, Lee DH, et al. The accuracy of icd codes for cerebrovascular diseases in medical insurance claims. Korean J Prev Med 2000;33:76-82.

39. Kim JY. Strategies to enhance the use of national health insurance claims database in generating health statistics. Seoul: Health Insurance Review \& Assessment Service; 2005.

40. Park BJ, Sung JH, Park KD, Seo SW, Kim SW. Strategies to improve the validity of diagnostic codes of national health insurance claims data. Seoul: Health Insurance Review \& Assessment Service; 2002. 